Article

\title{
Exploring Cross-Media Audience Practices in Two Cases of Public Service Media in Estonia and Finland
}

DE DE GRUYTER

OPEN

ALESSANDRO NANì, University of Tartu \& Tallinn University, Estonia;

email: alessandro.nani@tlu.ee

PILLE PRUULMANN-VENGERFELDT, Malmö University, Sweden;

email: pille.pruulmann.vengerfeldt@mah.se 


\section{ABSTRACT}

Stemming from the concept of active audiences and from Henry Jenkins' (2006) idea of participatory culture as the driving force behind the transformation of public service broadcasting into agencies of public service media (Bardoel, Ferrell Lowe 2007), this empirical study explores the attitude and behaviour of the audiences of two crossmedia projects, produced by the public service media of Finland (YLE) and Estonia (ERR).

This empirical study aims to explore the behaviour, wants and needs of the audiences of cross-media productions and to shed some light on the conditions that support the dynamic switching of the engagement with cross-media.

The study's results suggest that audiences are neither passive nor active, but switch from one mode to another. The findings demonstrate that audience dynamism is circumstantial and cannot be assumed. Thus, thinking about active audiences and participation as the lymph of public service media becomes problematic, especially when broadcasters seek generalised production practices. This work demonstrates how television networks in general cannot be participatory, and instead, how cross-media can work as a vehicle of micro participation through small acts of audience engagement (Kleut et al. 2017). 


\section{FROM PUBLIC SERVICE BROADCASTERS TO PUBLIC SERVICE MEDIA}

\begin{abstract}
People want to be included, and they want to be heard. Now they know how to make themselves heard, and if we want to be relevant in society, we need to talk to them by making our channels inclusive. We need new inclusive strategies to reach new types of audiences.
\end{abstract}

This imaginary quote from an imaginary television (TV) executive is what producers might have heard in production meetings worldwide, but is this an accurate statement? Is this what audiences want from public service broadcasters?

Today's media landscape is made of contradictory forces to which broadcasters are trying to adapt. If society is characterised by a 'lesser collective participation' (Bardoel, d'Haenens 2008:341), the individual contribution to the media discourse has reached new heights, and new breeds of audiences are today, more than ever, ready to engage in participatory production practices that, if not revolutionary, are the results of the society we live in today (Evans 2015: 111). Within this framework, on the one side, issues such as media saturation and audience fragmentation are viewed as concrete threats to the effectiveness of public service broadcasting in reaching and serving their publics. Seemingly on the other side, using digital media to include the publics is perceived by broadcasters as a way out. In fact, a number of academics (Jenkins 2006, Long 2007, Scolari 2009, Dena 2009) have started highlighting the behaviour of new types of audiences who are departing from linear broadcasting while embracing novel forms of active engagement. The challenge of less engaged societies and audiences that, at least in theory, are ready to interact and participate in media makes public broadcasters scramble for new productions. However, as the understanding of audience behaviour often relies on theoretical utopias rather than on tried and tested empirical investigations, the changes in TV networks result more from a trial-and-error approach than a systematic understanding of complex realities. This situation is evident in the transformation of public service broadcasting into agencies of public service media (Kjus 2007: 135).

On one hand, scholars have argued that public service broadcasting needs to seek new models for engaging citizens. For instance, Jo Bardoel and Gregory Ferrell Lowe (2007) claim that public service broadcasters must move beyond the broadcasting model to prioritise multimedia practices in the attempt to reach fragmented audiences and therefore to fulfil, once again, the remit they represent. Elisabeth Evans (2015) stresses how offering alternatives to TV broadcasting translates into offering audiences a wider range of choices in their engagement with the content produced by TV. Andres Jõesaar (2015: 81) argues that considering the young generation's departure from watching linear TV, broadcasters should reposition themselves and think in terms of converging media platforms, that is, cross-media strategies.

On the other hand, the broadcasters' leap into new inclusive strategies is often approximate, generic and contradictory. Indeed, if many European public service broadcasters have already shifted to public service media (Sehl et al. 2016), this does not necessarily translate into a good understanding of the implications caused by convergence and participation. Mark Andrejevic argues that "while audiences are active, the advent of interactive media is the development of strategies for promoting, harnessing, and exploiting the productivity of this activity' (Andrejevic 2008: 25). However, having a presence in social media and producing content for the internet cannot by itself be the answer to the oft-lamented loss of audiences. Sharon M. Ross remarks that 'the Internet has played a significant role in prompting the television industry to begin seeking viewer tele-participation' (Ross 2011: 72). However, tele-participation is 
often confined to forms of interaction, such as tele-voting and commenting. At least, as this study's findings demonstrate, this is not necessarily what makes the difference in the relationship between broadcasters and their audiences.

The lack of understanding of how to engage new audiences is demonstrated in the case of public service broadcasting in Estonia (ERR). Indrek Ibrus and Astra Merivee point out that despite the ERR executives' genuine interest in pursuing new cross-media strategies, approximation and the lack of comprehension clearly jeopardise the changes necessary to fulfil the public service remit (Ibrus, Merivee 2014: 117). The shift from public service broadcasting to public service media - inspired by the need to address irreversible societal changes that push people away from collective participation and simultaneously pull them towards individual participation should evolve around a clear understanding of audiences and audience practices.

\section{CROSS-MEDIA AND PUBLIC SERVICE MEDIA}

In this article, cross-media includes all activities that carry messages across platforms, aimed at catching audience attention, facilitating awareness and enhancing engagement (Ibrus, Scolari 2012). Social media platforms are among them, but news portals, websites and live events can also be considered to be cross-media. Crossmedia is an inclusive term that reflects the productions of the majority of European public service media and can be defined as the spreading of content across different media chosen for their characteristics, and where texts are related to each other, but are not necessarily linked by a unifying narrative that needs to be followed in its entirety to understand the individual components. Furthermore, cross-media is not related to the repurposing of the same content on different platforms, but the creation of unique content for a specific medium that, when put together, produces a coherent and plausible whole. The whole unit becomes the sum of different texts that are designed to intertwine and support one another. In cross-media, the audience is expected to have different degrees of engagement in the form of active interaction, and at its best, of participation (Gambarato, Nanì 2016). For John Fiske (1989), the conceptualisation of active audiences stems from the act of interpretation as a form of active engagement with the text. And while we presume that the active engagement with the text on the interpretational level is true across all audiences, in the case of cross-media environment, the audiences are invited to become active agents of composing their personal experiences. Based on Henry Jenkins' (1992) idea of participation, audience reactions, comments or involvement become part of the cross-media experience. Such active engagement shapes what Jenkins describes as participatory culture, a dimension where individuals are ready to migrate from one medium to another if they find the experience compelling enough and where fans depart from the mere consumption of media to embrace forms of organised and autonomous production of new texts (Jenkins 1992: 43). Such production occurs in the light of a culture of inclusion that propels audience engagement. Such engagement is not immune to exploitation, for instance, from the perspective of digital labour as discussed by Christian Fuchs and Sebastian Sevignani (2013) from a political economy perspective. However, the aim of this article is not necessarily critique, taking advantage of audiences as co-producers, but rather to investigate whether the audiences recognise such invitations in the first place. As demonstrated in the following sections, if we limit the cross-media experience to active re-appropriation of content as defined by Jenkins, we lose out on an in-depth understanding of the nuances of audience behaviour. Participatory culture thus comprises a set of ideas, customs and social behaviours that, sustained by new media technologies, enhance the involvement of people in media and more generally, in society. 


\section{DYNAMIC AUDIENCE}

Audiences have been studied and conceptualised from different angles (Abercrombie, Longhurst 1998). Without joining the almost exhausted debate on the legitimate use of the term 'audience', we feel compelled to stress that even if audiences have historically been associated with being receivers, hence spectators, viewers or listeners, the reality has changed today:

the more individuals are free and able to compose their own media 'diets' as a result of new technology, the more such types of audience will emerge, having no clear definition in terms of social categories, but held together, nevertheless, by a convergence of cultural tastes, interests of information needs. (McQuail 1997: 22-23)

Although Denis McQuail's argument is relevant, the idea of being held together is, if not incorrect, at least imprecise. Actually, even if individuals are part of an audience due for instance to certain cultural tastes that hold them together, tastes can change and preferences are often circumstantial. Sonia Livingstone (2013) suggests that an audience is such only within a specific time, space and circumstance; hence, it should be regarded as a dimension rather than a fixed and established entity. Sherryl Wilson proposes the need for a new conceptualisation of audiences 'that accommodates the idea that audiences' attention will vary according to genre, social circumstance, and mood' (Wilson 2016: 187). Furthermore, the need for a new conceptualisation of audiences should not hint at the need to find a superior model of an audience; indeed, it should bridge old and new where one is not better than the other. In the recent past, a certain tension has (re-) emerged between the concepts of passive and active audiences, where the latter has often been favoured (Nightingale 2011: 2). Nico Carpentier argues that 'we are often led to believe that all audiences of participatory media are active participants, and that passive consumption is either absent or regrettable' (Carpentier 2011: 200). However, in the light of the fluidity of audiences, we suggest that a dynamic audience is neither passive nor active per se, neither worse nor better, but dynamically transforming and adapting to different stimuli. Therefore, the very idea of an audience as a stable group is superseded, favouring instead the idea of individuals adopting practices that belong to a certain group, rather than the individuals themselves necessarily forming such a group.

Even in the case of self-identification with a certain group, such as individuals identifying themselves as fans of something, an individual should not be framed as a fan; rather, his or her actions should be considered practices that might reflect a certain common behaviour. The use of the word 'fans' indicates 'a wide range of ordinary people who [have] positive emotional engagement with popular culture' (Duffett 2013: 17). In this context, we feel compelled to highlight the ordinary rather than the extraordinary. Thus, a fan is firstly an individual who is interested in a text at a given moment, which might be long or short, and under particular circumstances. While there might be different views, this self-identification with practices rather than with groups helps notice the people who are not organised according to groups or communities but still share a common set of practices.

Engagement can vary to great degree, and we hereby propose differentiating among three degrees of cross-media engagement. The first encompasses what Kim C. Schrøder (2011) calls inherently cross-media audience behaviour - people follow news and other media across different channels to compose their own experiences. This behaviour demonstrates unmindful cross-media consumption. The second degree involves active cross-media consumption, where the audience starts to actively follow and seek different crossmedia linkages provided by a producer. The third degree occurs when audiences become part of the media production. 
However, sharing the same code does not necessarily translate into sharing the same understanding or appropriation of a given message. Here is where Umberto Eco's (1990) idea of interpretation (and its limits) becomes useful because it is based on the belief that a shared code is not a sufficient guarantee against polysemic meanings, and we might add, against polysemic behaviours.

The diverse ways to appropriate a given message brings us to the concept of affordance as introduced by James J. Gibson. He argues that "the affordances of the environment are what it offers the animal, what it provides or furnishes, either for good or ill' (Gibson 1979: 127). For Gibson, an affordance exists independently of the actor's ability to recognise it; nevertheless, it is dependent on the action capabilities of the same individual. For instance, to a technology-savvy individual, a mobile app can have an affordance of interaction, but the same affordance is missing from a technology-inept person who lacks the required action capability. This means that cross-media affordances are such if the audience is potentially capable of engaging with them. Relating Gibson's argument to Eco's (1990) theory, we argue that this type of affordance denotes a message that exists per se but is interpreted in a correct way only in the presence of a shared code. However, Gibson's visions do not contemplate the possibility of an alternative interpretation, hence of a polysemy of connotations. However, in borrowing Donald A. Norman's popular re-interpretation of affordance, originally introduced in 1988 in his book The Psychology of Everyday Things, the issue of a polysemy of connotations is promptly addressed. For Norman, 'affordances refer to the potential actions that are possible, but these are easily discoverable only if they are perceivable: perceived affordances' (Norman 2013: 145). As Joanna McGrenere and Wayne Ho suggest, in Norman's interpretation of affordance, 'an individual may be involved in characterising the existence of the affordance' (McGrenere, Ho 2000: 181). If an affordance is perceived, it can only be the result of the cultural baggage that each individual bears. Perception is culturally driven; hence, it implicitly carries a polysemy of meanings as Eco (1990) suggests. We now further investigate the cross-media affordances as perceived by the audience.

\section{EMPIRICAL RESEARCH ON THE BEHAVIOUR OF CROSS-MEDIA AUDIENCES}

Given that an audience constitutes a dynamic dimension, the division of participants into groups and subgroups might still be useful to the practical side of an empirical investigation. In this research as well, the audiences were approached through preconditioned groups and invited to discuss issues in a focus-group environment, where it was assumed that a shared background would make it easier to share experiences. However, the data should be analysed with the awareness that practices matter and might vary even among individuals clustered in the same group, and such clustering does not represent the only established status of the group members.

Current empirical work explores the behaviour, wants and needs of the audiences of cross-media productions. While 'audiences are inherently cross-media' (Schrøder 2011), composing their own stories of reality from diverse media representations, are they ready to embrace the participatory model within productions that are developed, created and distributed by public service media?

With this objective in mind, we selected two productions: Eesti laul (Estonian Song), the pop-song contest produced by the Estonian public service broadcaster ERR, and Puoli seitsemän (Half Past Six), an evening magazine-type, cross-media programme produced by YLE, the Finnish public service media.

Eesti laul is an annual event aimed at showcasing Estonian singers and selecting the national representative for the Eurovision Song Contest. The cross-media production consists of three TV shows - two semi-finals that take place in ERR's main TV 
studio and one final live event in the Saku Suurhall, Estonia's largest indoor arena that accommodates approximately 10,000 people - that are all broadcast live on ETV, the main TV channel of ERR.

In addition to these three shows, other ERR TV programmes and ERR channels contribute to the cross-media pallet of Eesti laul. ETV+, a Russian-language channel launched in 2016, had special live coverage of the event. Similarly, Raadio2 had a live broadcast of the event. ETV's breakfast programme Terevisioon and an evening infotainment programme Ringvaade contribute introductory feature stories before the semi-finals and interviews with artists during the period covering the three shows. The cross-media plateau includes an online presence consisting of a dedicated website, a Facebook page that features posts written in Estonian and English, as well as Twitter and Instagram accounts.

Moreover, the entire cross-media is not confined to ERR. In fact, Eesti laul has challenged the original idea of public service media by forming a partnership with Postimees, the largest private daily newspaper in Estonia. The printed and online versions of Postimees have dedicated inserts and offer unique access to artists and content.

Puoli seitsemän is a factual magazinetype, daily TV show aired on YLE's main channel YLE1, with inserts on radio broadcasts, a number of live events, webisodes and a presence on Facebook, Instagram and Twitter. Furthermore, Puoli seitsemän produces episodes covering several weeks, with themes focusing on specific issues, such as ornithology, fishing, and so on. During these thematic weeks, the programme features special inserts on radio broadcasts, organises specific events and creates 'small acts of audience engagement' (Kleut et al. 2017: 28), such as inviting audiences to build their own birdhouses and then share their images with relevant comments, on Puoli seitsemän's social media pages.

The selection of works from two different countries provides a speculative picture of the current situation. Cross-media is still a rather new phenomenon; hence, we could not find multiple case studies from the same organisation. Certainly, both media organisations (ERR and YLE) have productions that unfold on different platforms. However, several meetings with the management of the two organisations have demonstrated that the two selected samples best represent the definition of cross-media and best fit the aims and the description of public service media. Furthermore, considering that this study is not intended to be comparative, the selection of two examples from Finland and Estonia, regardless of the differences in their media systems (Hallin, Mancini 2012), show quite similar patterns of media consumption, such as TV viewing hours and internet penetration percentages (Standard Eurobarometer 2016). Thus, this paper provides insights into the audience practices of two neighbouring countries.

The data were collected through seven focus groups, divided into four groups with a total of 21 participants representing Puoli seitsemän and three groups with a total of 27 participants representing Eesti laul. The number of focus groups and their typology were based on previous discussions with the producers of the two shows that resulted in the conceptualisation of their audiences. In fact, in the case of Puoli seitsemän, the participants were selected through an agency and personal recruitment in order to assemble groups of people that the producers identified as potential audiences (specifically, young men, mothers of pre-kindergarten children and young working women), as well as through a Facebook invitation to active followers of the programmes.

Aside from having followers, as does Puoli seitsemän, Eesti laul's case was in some ways singular because of the existence of an official fan club (an association recognised by the producers and therefore officially accredited to represent Estonia at the Eurovision Song Contest), whose members were invited to be part of a separate focus group for two reasons. Firstly, in practical terms, we wanted to keep the number of participants manageable but still large 
enough to allow for the possibility of diverse opinions and views. Secondly, we recognised the opportunity to observe whether belonging to an institutionalised community would demonstrate a different behavioural pattern compared with a more casual or non-organised following. Since the interviews indicated that the producers' conceptualisation of the audiences included people who could understand Estonian, the third focus group was comprised of individuals of both genders, ranging in age from 16 to 60 years and referred to here as the general Estonian population. The focus group participants were selected through personal contacts, followed by the snowballing method, and through announcements on the Tallinn University and the ERR Facebook pages. Unlike the other two, the participants belonging to the Fans of Eesti laul focus group were suggested by the leaders of the fan club.

\section{FROM TV SHOW TO WATCHING TO A WILLINGNESS TO ENGAGE, IF THE CONDITIONS ARE RIGHT}

The findings indicate a dissonance between the possibility of theoretical engagement of audiences across platforms and their actual engagement with cross-media.

The audiences of both productions equally indicate that the perception of what constitutes TV, and thus the associated practices, plays a relevant role in the audiences' willingness to engage in participatory practices typical of cross-media.

Both Puoli seitsemän and Eesti laul are perceived by their audiences as TV programmes, and although some focus group participants recognise their multiplatform nature, they still mainly refer to the programmes as TV shows. Such de-codification shapes the immediate degree and nature of engagement that individuals are ready to share with the text. Based on Norman's (2013) argument, we suggest that crossmedia-perceived affordances are shaped by several factors that are culturally and circumstantially dependent. In this study, we investigate some of the affordances as relationships among the behaviour, wants and needs of the audiences of cross-media productions, and the different ways that they support audience engagement with the texts.

First, cross-media-perceived affordances are influenced by a silent agreement between producers and their audiences regarding modes of engagement with different media. The focus groups indicate that the majority of the participants associate TV with the act of viewing, hence with a sort of passive attitude towards the text or the process of viewing. For instance, Puoli seitsemän is described with comments such as 'relaxing on the couch', and the engagement with it is described with statements such as 'I don't need any interaction when I'm watching TV; I like that it's passive', and 'I think that I don't need anything more than watching TV'. This perspective links their practices mostly to the first level of engagement where casual cross-media engagement may occur but is not recognised by audiences as such.

For some participants, Eesti laul follows similar patterns, where people claim it to be 'a TV show to watch'. For others, the competitive nature of the event and the relevance of its outcome (Estonia being represented at the Eurovision Song Contest) lead to different interpretations. For example, fans describe it with arguments such as 'I think it is so much more than a TV show', and 'It creates tsunamis in social media'. Thus, there is a greater recognition of its cross-media nature as many study participants perceive Eesti laul as an annual event that is aired on TV, but audiences play a decisive role in shaping the outcome of the show. In fact, when asked what Eesti laul is, all participants readily agree that Eesti laul involves the selection of an Estonian song that will represent the country at the Eurovision Song Contest. The association of Eesti laul with TV, especially by the general public and the followers, emerges only at the second stage when they are asked what Eesti laul is in media terms. This means that Eesti laul audiences actively recognise that the concert is the potential main event and the TV show is a cross-media add-on to 
allow people to follow the production. The audiences also explicitly mention seeing Eesti laul everywhere, meaning that they notice the cross-media element even if they do not seek out and follow the production. In fact, when asked where he notices Eesti laul in the media, a participant belonging to the followers' focus group said:

Participant: Mm.... I don't know.
I get most of my information from
Postimees.
Interviewer: So, did you notice
Eesti laul in Postimees?
Participant: Of course. It was full
of it.

Even more illustrative is the comment from one Eesti laul fan: 'You get it [Eesti laul] from everywhere.'

The main difference from Puoli seitsemän is that the Eesti laul show's interactive component is immediately recognised by its audience; thus, the third level of engagement, where audience participation is part of the programme, is also appreciated by the audience. The Eesti laul winner is indeed decided by the votes of the jury (comprising experts) and the public's televote in a system that first determines who among the pre-selected artists will advance from the semi-finals to the finals and then selects the winner. Audience engagement via call-in votes is appreciated and recognised as participation. However, the other cross-media dimensions of Eesti laul remain by and large unnoticed and unrecognised. Thus, while voting is recognised as participation in the process of making Eesti laul, other cross-media participation possibilities (such as engagement in social media) are less realised.

Second, perceived affordances of cross-media depend on the recognition of relevance and expertise. If a certain text is considered interesting, an individual might be willing to engage in cross-media possibilities in addition to the primary text, and audiences might be ready to get involved in the participatory elements of the production. However, this expec- tation becomes more unrealistic when applied to Puoli seitsemän. The members of the audience do not think that the Puoli seitsemän texts are specialised (thus in this case, also motivating) enough to be trusted with deeper engagement on a given topic. The participants in one of the focus groups referred to Top Gear (the popular car show produced by BBC) claiming that they would engage with its content across platforms because they trust the expertise of Top Gear. However, they would not want to engage with the daily magazinetype Puoli seitsemän because as a generic programme, it has not generated enough content-related trust to warrant the audience's shift from passive consumption to active engagement. Thus, people might still be following Schrøder's (2011) idea of making their own experiences cross-mediatic, but not necessarily by engaging with the opportunities provided by the public service broadcaster.

Third, cross-media-perceived affordances are genre dependent. Audience members also draw attention to the different attitudes towards cross-media, depending on the genre. The case of Top Gear, that is a highly specialised format, and other comments demonstrate that, while the cross-media approach might work for one production, it might not work for another.

Fourth, cross-media-perceived affordances rely on the distribution strategies and tools. In case of TV programmes, the choice of the time slot is well recognised as being relevant to their success; in crossmedia, this aspect becomes even more evident. Cross-media implies the use of different media that, in certain cases, should occur simultaneously. This is the case in the second-screening practices, such as tweeting and tele-voting, of Eesti laul.

The Eesti laul TV show is aired in the evening during prime time when presumably, viewers can pay attention to it and possibly engage beyond TV in the form of interaction with the programme. The body of the data from Eesti laul does not show any conflicts in the time-slot-interaction relation, which indicates that for this type 
of programme, this type of interaction, the presumption has worked and people recognise the affordance. However, in the case of Puoli seitsemän, a number of comments highlight the difficulties. The programme is aired at 6:30 pm, a time when families (e.g., those with young children) are engaged in various activities, such as preparing food, eating and playing with the kids. Thus, at this time, TV acts as a background for other activities. To assume that viewers would want to interact with cross-media content in these cases, when the TV is turned on but is not the centre of the viewers' attention, becomes rather unrealistic.

One mother clearly illustrates the function of TV in the early evening:

Pikku Kakkonen [a programme for children] is [shown] every day at 5 o'clock, and it's a convenient time to [prepare] food; ...it is very easy to cook while the kids are watching Pikku Kakkonen. [---] I think it's something that YLE has considered in their scheduling, but besides that, I think there is no need for TV in our family. I watch a TV series when I have some free time after the kids are asleep, and two hours before I go to bed. Then I want to watch exactly what I want, not something like, okay, maybe this is interesting.

Thus, even if topical engagement might be possible, the unsuitability of the timeslot and lack of specificity has made it impossible for this young mother to meet the expectation of the broadcaster.

These four conditions for crossmedia affordances, and more specifically, perceived affordances, demonstrate that cross-media strategies should be specific and circumstantial and not generalised. In fact, this contrasts with the various policies and arguments promoting general strategies aimed at enhancing the shift towards public service media. To provide just one example of general cross-media strategies, consider ERR where the management rec- ognises the need for cross-media while failing to fully understand its practices (Ibrus, Merivee 2014). Darja Saar (2015), the director of one of the ERR TV channels (which was launched in September 2015), officially argued in favour of shaping it into an innovative cross-media channel. Even the press release was entitled 'Igaüks on oluline! Sinust sõltub!' ('Everyone is important! It depends on you!'), pointing to the general, allencompassing engagement idea. However, as this study's findings indicate, the aspiration for a generic cross-media channel is contrasted with the audience-perceived affordances of cross-media. Thus, if we plan to achieve the ideal of considering everyone to be important, then the general 'everyone' needs to be divided into specific 'someones' whose needs are met by diverse cross-media activities, in which the discussed four types of affordances - the positioning of medium, relevance and expertise, genre and distribution strategies - are considered.

\section{CONCLUSIONS}

The theory section has included a discussion of the dichotomy between a society with declining collective participation and the blossoming of new types of audiences who want to be heard while seeking possibilities for individualised participation. Topped by an evident fragmentation of audiences, this situation has prompted the shift from public service broadcasting to public service media. However, media networks have done so without any clear strategies or clear understandings of audiences and their needs. The theoretical discussions about the issues of cross-media have been limited to production and the offering of cross-media content, while not critically questioning why and under which circumstances the audiences would want to engage with cross-media production. There has also been limited discussion and understanding about what it means to be engaged with cross-media production. Hopefully, this article will provide initial ideas leading to a critical examination and recognition of audience activities. 
Citing two examples, this empirical study has discussed how a cross-media approach (e.g. having an internet presence and producing across different media platforms) does not necessarily mean reaching the audience and overcoming fragmentation.

The default TV-watching mode for the entertainment productions discussed here seems to be relaxed and the mere processing of content. The cross-media dimension can easily be dismissed or ignored if the conditions are not right. Thus, the perceived default for engagement is reading/viewing, while the audience's cross-media experiences are being put together without much conscious thought or any recognition of the producers' efforts. To engage audiences in cross-media to a greater degree - as active seekers of content or even participants through sharing or commenting - greater efforts need to be made by the cross-media producers. The audiences are unwilling to engage in one-model-fits-all approaches as their attitudes depend on whether they perceive the engagement partner to be worthy of their trust. As the findings demonstrate, the cross-media affordances are shaped by a number of factors that might not only hinder the recognition of the production as a cross-media type, but even result in forms of conflicting interpretations. Audiences prefer specific engagements to more generic ones and are more likely to follow expert knowledge than general journalistic content.

The list of the four perceived affordances is by no means exhaustive; there can be more, especially as those we have found indicate high specificity. This means that different types of production and modes of engagement need to be discussed and studied further. The proposed division into three degrees of participatory engagement employs a wide variety of practices and ignores the power-related dimension of participatory engagement as discussed by Carpentier (2011). To properly address this limitation, further studies are needed.

This work has not touched on the economic aspects of the trial-and-error approach when using public funds. However, it seems obvious that especially with limited budgets, such as in the case of ERR (Ibrus, Merivee 2014), the balance between innovation, experimentation and sound decisions should be carefully considered and benchmarked against research and previous experiences. 


\section{REFERENCES}

Abercrombie, Nicholas; Longhurst, Brian J. 1998. Audiences: A Sociological Theory of Performance and Imagination. London: Sage.

Andrejevic, Mark 2008. 'Watching Television Without Pity: The Productivity of Online Fans'. - Television \& New Media 9, 1, 24-46.

Bardoel, Jo; Ferrell Lowe, Gregory 2007. 'From Public Service Broadcasting to Public Service Media: The Core Challenge'. - Gregory Ferrell Lowe, Jo Bardoel (eds.), From Public Service Broadcasting to Public Service Media. Göteborg: Nordicom, 9-26.

Bardoel, Johannes; d'Haenens, Leen 2008.

'Reinventing Public Service Broadcasting in Europe: Prospects, Promises and Problems'. - Media, Culture \& Society 30, 3, 337-355.

Carpentier, Nico 2011. 'New Configurations of the Audience? The Challenges of User-Generated Content for Audience Theory and Media Participation: Virginia Nightingale (ed.), The Handbook of Media Audiences 5. Malden: Wiley-Blackwell, 190-212. Dena, Christy 2009. Transmedia Practice: Theorising the Practice of Expressing a Fictional World Across Distinct Media and Environments. PhD thesis. University of Sydney.

Duffett, Mark 2013. Understanding Fandom: An Introduction to the Study of Media Fan Culture. New York: Bloomsbury.

Eco, Umberto 1990. I limiti dell'interpretazione. Milano: Bompiani.

Evans, Elisabeth 2015. 'Layering Engagement: The Temporal Dynamics of Transmedia Television'. Storyworlds: A Journal of Narrative Studies 7, 2, 111 128.

Fiske, John 1989. 'Moments of Television'. - Ellen Seiter, Hans Borchers, Gabriele Kreutzner, Eva-Maria Warth (eds.), Remote Control: Television, Audiences, and Cultural Power. London: Routledge, 56-78.

Fuchs, Christian; Sevignani, Sebastian 2013. 'What Is Digital Labour? What Is Digital Work? What's Their Difference? And Why Do These Questions Matter for Understanding Social Media?' - TripleC: Communication, Capitalism \& Critique: Open Access Journal for a Global Sustainable Information Society 11, 2, 237-293. Gambarato, Renira Rampazzo; Nanì, Alessandro 2016. 'Blurring Boundaries, Transmedia Storytelling and the Ethics of CS Pierce.' - Steven Maras (ed.), Ethics in Screenwriting: New Perspectives. London: Palgrave Macmillan, 147-175.

Gibson, James J. 1979. The Ecological Approach to Visual Perception. Boston: Houghton Mifflin. Hallin, Daniel; Mancini, Paolo 2012. Comparing Media Systems Beyond the Western World. Cambridge: Cambridge University Press.

Ibrus, Indrek; Merivee, Astra 2014. 'Strategic Management of Crossmedia Production at Estonian Public Broadcasting. - Baltic Screen Media Review 2, 96-120. Ibrus, Indrek; Scolari, Carlos A. 2012. Crossmedia Innovations: Texts, Markets, Institutions. Frankfurt am Main: Peter Lang.

Jenkins, Henry 1992. Textual Poachers: Television Fans and Participatory Culture. New York: Routledge. Jenkins, Henry 2006. Convergence Culture: Where the Old and New Media Collide. New York: New York University Press.

Jõesaar, Andres 2015. 'PSM - Home Alone in a Narrowcasting Era? A Case Study: The Estonian Public Broadcasting'. - Informacijos mokslai 70, 69-84. Kjus, Yngvar 2007. 'Ideals and Complications in Audience Participation for PSM: Open Up or Hold Back?' - Gregory Ferrell Lowe, Jo Bardoel (eds.), From Public Service Broadcasting to Public Service Media. Göteborg: Nordicom, 135-150.
Kleut, Jelena; Møller Hartley, Jannie; Pavlíčková, Tereza; Picone, Ike; Romic, Bojana; De Ridder, Sander 2017. 'Small Acts of Audience Engagement Interrupting Content Flows'. - Ranjana Das, Brita Ytre-Arne (eds.), Audiences, Towards 2030: Priorities for Audience Analysis. Surrey: CEDAR, 28-30.

Livingstone, Sonia 2013. 'The Participation Paradigm in Audience Research'. - The Communication Review 16, 1-2, 21-30.

Long, Geoffrey 2007. 'Transmedia Storytelling: Business, Aesthetics and Production at the Jim Henson Company' MA thesis. Massachusetts Institute of Technology. Cambridge, MA.

McGrenere, Joanna; Ho, Wayne 2000. 'Affordances: Clarifying and Evolving a Concept'. - Proceedings of Graphics Interface, 179-186.

McQuail, Denis 1997. Audience Analysis. Thousand Oaks: Sage.

Nightingale, Virginia (ed.) 2011. The Handbook of Media Audiences 5. Malden: Wiley-Blackwell.

Norman, Donald A. 2013. The Design of Everyday Things. Revised and expanded edition. New York: Basic Books. Ross, Sharon M. 2011. Beyond the Box: Television and the Internet. Malden: John Wiley \& Sons.

Saar, Darja 2015. 'Igaüks on oluline! Sinust sõltub!' ERR. http://info.err.ee/l/avalikteave/venekeelne_ telekanal (1 September 2017).

Schrøder, Kim C. 2011. 'Audiences Are Inherently Cross-Media: Audience Studies and the Cross-Media Challenge.' - Communication Management Quarterly $18,6,5-27$.

Scolari, Carlos Alberto 2009. 'Transmedia Storytelling: Implicit Consumers, Narrative Worlds, and Branding in Contemporary Media Production'. - International Journal of Communication 3, 586-606.

Sehl, Annika; Cornia, Alessio; Nielsen, Rasmus K. 2016. Public Service News and Digital Media. Oxford: Reuters Institute for the Study of Journalism. http://reutersinstitute.politics.ox.ac.uk/sites/default/files/research/ files/Public\%2520Service\%2520News\%2520and\%252 ODigital\%2520Media.pdf (9 November 2017).

Standard Eurobarometer 2016. Standard Eurobarometer 86: Media Use in the European Union. Report. S.l.: European Commission. https://publications.europa.eu/ en/publication-detail/-/publication/7b345c9d-6b6411e7-b2f2-01aa75ed71a1/language-en (19 November 2017).

Wilson, Sherryl 2016. 'In the Living Room: Second Screens and TV Audiences'. - Television \& New Media 17, 2,174-191. 